\section{Recommendations for Preventing Hepatitis C Virus Infection: Analysis of a Brooklyn Endoscopy Clinic's Outbreak}

\section{To the Editor:}

On June 8, 2001, New York City health officials reported a nosocomial outbreak of the hepatitis $\mathrm{C}$ virus (HCV). ${ }^{1}$ At least nine patients who underwent gastrointestinal (GI) endoscopy at a clinic in Brooklyn tested positive for $\mathrm{HCV}$. Initial reports suggested that one of these nine patients was infected at the clinic in January 2001 , and the other eight were infected 2 months later during the last few days of March. It is unclear whether the $\mathrm{HCV}$ infection in January was related to the HCV outbreak in March.

Authorities have recommended that all patients who underwent upper and lower GI endoscopy at the Bay Ridge Endoscopy and Digestive Health Center in Brooklyn, between January 2000 (when the clinic opened) and May 1, 2001 (when the outbreak was discovered and the clinic closed), should be serologically tested for HCV infection. As many as 2,200 patients may be at risk. This outbreak appears to be isolated to this clinic and is not believed to pose a risk to the general public.

New York City and New York State health officials currently are investigating this $\mathrm{HCV}$ outbreak. ${ }^{1}$ To date, neither state nor city health officials have completed their investigation or publicly released any information regarding possible cause(s) of this $\mathrm{HCV}$ outbreak. Although the source of the HCV outbreak at the Brooklyn clinic has not been determined to date, investigations of other $\mathrm{HCV}$ outbreaks usually have implicated the healthcare center's failure to adhere strictly to published infection control practices and Standard Precautions. . Based on the identified causes of these previously reported outbreaks, the cause(s) of this Brooklyn clinic's outbreak likely will be linked to at least one of the following factors: (1) sharing contaminated multidose anesthetic vials, intravenous supplies, tubing lines, or syringes (as may be used to achieve conscious sedation) among patients ${ }^{3,4}$; (2) inadequate cleaning or disinfection of GI endoscopes ${ }^{3,4}$; (3) inadequate cleaning or sterilization of biopsy forceps or other endoscopic accessories ${ }^{3}$; or (4) inadequate deconta- mination of the clinic's environmental surfaces. When reprocessed (washed and disinfected or sterilized) according to standard recommended protocols, reusable endoscopic instrumentation poses a very low risk of patient infection. ${ }^{1}$

The hepatitis $\mathrm{C}$ virus is the most common chronic blood-borne infection in the United States ${ }^{5}$ and can cause liver damage, cirrhosis, and hepatocellular carcinoma. Symptoms of $\mathrm{HCV}$ infection, which may occur within 2 weeks to 6 months after exposure, include loss of appetite, nausea, fatigue, and jaundice. Immunization against HCV currently is not available. ${ }^{5}$ Due to the introduction of screening programs several years ago in the United States, the risk of $\mathrm{HCV}$ infection from a blood transfusion has been reduced to approximately 1 in $100,000 .^{6}$ Although the source and mode of $\mathrm{HCV}$ transmission can be difficult to determine, $\mathrm{HCV}$ infection following direct percutaneous exposure to contaminated blood in the healthcare setting has been reported. ${ }^{6}$ Blood transfusions, drug injections, and hemodialysis are medical procedures that particularly place patients at risk of infection by $\mathrm{HCV}$ and other blood-borne pathogens. ${ }^{5,6} \mathrm{HCV}$ infection during GI endoscopy has been reported only a few times. 3,4

The following recommendations minimize the risk of patient infection by $\mathrm{HCV}$ and other blood-borne pathogens during flexible endoscopy and other surgical procedures:

1. Ensure that healthcare personnel are thoroughly educated on potential modes of transmission of $\mathrm{HCV}$ and adhere strictly to published infection control recommendations and Standard (Universal) Precautions., 2,6

2. Perform a standardized, validated, and published endoscope decontamination (eg, cleaning, disinfection) procedure that accounts for all of the endoscope's surfaces, including each of its valves and internal channels and structures., 3

3. Steam sterilize all reusable biopsy forceps and other endoscopic accessories (after ultrasonic cleaning). ${ }^{3}$

4. Use, handle, and dispose of needles and other sharp instruments carefully.

5. Separate clean supply areas from areas where used supplies are handled or contaminated instruments are reprocessed. ${ }^{5}$

6. Wash hands frequently, and practice good hygiene at all times.
Clean and disinfect all surfaces that may become contaminated with $\mathrm{HCV}$.

7. When administering an anesthetic (eg, propofol) during endoscopy, adhere to strict aseptic techniques when handling anesthetic vials. ${ }^{8}$ Because hands and gloves have been reported to transmit $\mathrm{HCV}$, wear new ones for each patient. ${ }^{5,6}$ Also, reusing medicine vials, intravenous tubing lines, and/or syringes is a risk factor for patient infection. ${ }^{3,4}$ Therefore, use a single-dose anesthetic vial and disposable tubing line and syringe for each patient (in general, use disposable items whenever possible) ${ }^{3,8}$; do not puncture single-use intravenous medication vials more than once for repeated anesthetic administration ${ }^{9}$; do not pool residual medication from two or more vials into a single vial (eg, the anesthetic propofol has been shown to be a medium for the growth of Serratia marcescens ${ }^{8}$ ); and refrain from filling multiple syringes with the anesthetic at one time for use throughout the course of the day. ${ }^{8}$

\section{REFERENCES}

1. Muscarella LF. Sterilize that device. Newsday Thursday, August 2, 2001:A41. Letter.

2. McLaughlin KJ, Cameron SO, Good T, McCruden E, Ferguson JC, Davidson F, et al. Nosocomial transmission of hepatitis $\mathrm{C}$ virus within a British dialysis center. Nephrol Dial Transplant 1997;12:304-309.

3. Bronowicki JP, Venard V, Botte C, Monhoven $\mathrm{N}$, Gastin I, Chone L, et al. Patient-to-patient transmission of hepatitis $\mathrm{C}$ virus during colonoscopy. N Engl J Med 1997;337:237-240.

4. Le Pogam S, Gondeau A, Bacq Y. Nosocomial transmission of hepatitis C virus. Ann Intern Med 1999;131:794.

5. Centers for Disease Control and Prevention. Recommendations for prevention and control of hepatitis C virus (HCV) infection and HCVrelated chronic disease. MMWR 1998;47(RR19):1-39.

6. Knoll A, Helmig M, Peters O, Jilg W. Hepatitis $C$ virus transmission in a pediatric oncology ward: analysis of an outbreak and review of the literature. Lab Invest 2001;81:251-262.

7. Society of Gastroenterology Nurses and Associates. Standards of infection control in reprocessing of flexible gastrointestinal endoscopes. Gastroenterology Nursing 2000;23:172179.

8. Henry B, Plante-Jenkins C, Ostrowska K. An outbreak of Serratia marcescens associated with the anesthetic agent propofol. Am I Infect Control 2001;29:312-315.

9. Centers for Disease Control and Prevention. Recommendations for preventing transmission of infection among chronic hemodialysis patients. MMWR 2001;50(RR-5):1-46.

Lawrence F. Muscarella, $\mathbf{P h D}$ Custom Ultrasonics, Inc Ivyland, Pennsylvania 